\title{
Gastric gland metaplasia in the small and large intestine
}

\author{
I. YOKOYAMA, S. KOZUKA, K. ITO, K. KUBOTA, Y. YOKOYAMA, AND \\ T. KONDO
}

From the Second Department of Surgery and the Second Department of Pathology, Nagoya University School of Medicine, Nagoya, and the Yokoyama Gastrointestinal Hospital, Nagoya, Japan

SUMMARY Fifty-six surgical specimens with various ulcerative intestinal disorders were microscopically investigated for evidence of gastric gland metaplasia. Thirty-one specimens $(55.4 \%)$ showed pyloric gland metaplasia. Among the 31 patients with pyloric gland metaplasia, five showed true gastric metaplasia, consisting of parietal cells, chief cells, and mucous neck cells. The percentage of true gastric metaplasia among pyloric gland metaplasia was as high as $16 \%$, an overall frequency of $9 \%$ among various ulcerative intestinal disorders. The mechanism of pyloric gland metaplasia and true gastric metaplasia is not understood, but may occur secondary to submucosal response to ulcer healing and subsequent alteration of the intraluminal condition in the intestine.

A congenital type of aberrant gastric gland-that is, gastric heterotopia in the intestine-has been frequently encountered in patients with Meckel's diverticulum, less frequently with intestinal duplication (Ripstein, 1949; Stockman et al., 1960; Duffy et al., 1974) and other miscellaneous conditions (Lee et al., 1970), while the acquired type of gastric gland-that is, gastric metaplasia-has rarely been found. Several authors have reported on pyloric gland metaplasia in various intestinal disorders (Liber, 1951; Antonius et al., 1960) and a few authors have reported on gastric metaplasia in the duodenum (James, 1964; Hoedemaeker, 1970). True gastric metaplasia in the intestine below the ligament of Treitz, however, had not been reported until 1963 when Ming et al. (1963) described a case of regional ileitis in which they encountered parietal and chief gastric cells in the metaplastic glands. Another report by Trier et al. (1973) was on ectopic gastric mucosa in the jejunum with coeliac sprue, although it was uncertain whether it was acquired in orgin or not. The latest report by Nawaz et al. (1974) was also concerned with true gastric metaplasia in the ileum with ulceration and chronic bleeding.

In the present study, we found five cases of gastric metaplasia consisting of parietal cells, chief cells, and

Address for correspondence: Dr Itsuo Yokoyama, The Second Department of Surgery, Nagoya University School of Medicine, 65 Tsurumacho, Showaku, Nagoya, 466, Japan.

Received for publication 6 December 1976. mucous neck cells among 31 cases which exhibited pyloric gland metaplasia in the small and large intestine.

\section{Methods}

A series of 56 specimens of intestinal disorders showing benign ulcerative lesions was investigated for evidence of gastric metaplasia. All the surgical specimens were selected from patients who were admitted from 1965 to 1975 to the Second Department of Surgery at Nagoya University School of Medicine and the Yokoyama Gastrointestinal Hospital, Nagoya, Japan. Neither biopsy specimen nor post mortem materials was included in this study.

In the interpretation of histological lesions, the term 'pyloric gland metaplasia' was used for glands resembling those of the pyloric region, and the term 'true gastric metaplasia' for glands consisting of parietal cells, chief cells, and mucous neck cells.

\section{Results}

Of the total 56 specimens, pyloric gland metaplasia of varying degrees was demonstrated in $31(54.4 \%)$ as shown in the Table. The age distribution was from 15 to 70 years with a mean age of $42 \cdot 3$ years. It was noted that 15 of 18 specimens with tuberculosis $(83.3 \%)$ and 11 of 17 with Crohn's disease (64.7\%) of the small intestine showed pyloric gland metaplasia. Although no specimens of tuberculosis in the 
Table Frequency of pyloric gland metaplasia and true gastric metaplasia

\begin{tabular}{|c|c|c|c|c|c|}
\hline \multirow{2}{*}{$\begin{array}{l}\text { Disease } \\
\text { Small intestine }\end{array}$} & \multirow[t]{2}{*}{$\begin{array}{l}\text { No. of } \\
\text { case } \\
\text { examined }\end{array}$} & \multicolumn{2}{|c|}{$\begin{array}{l}\text { Pyloric gland } \\
\text { metaplasia } \\
\text { (no.) }(\%)\end{array}$} & \multicolumn{2}{|c|}{$\begin{array}{l}\text { True gastric } \\
\text { metaplasia } \\
\text { (no.) (\%) }\end{array}$} \\
\hline & & & & & \\
\hline Tuberculosis & 18 & 15 & $83 \cdot 3$ & 3 & $16 \cdot 7$ \\
\hline $\begin{array}{l}\text { Crohn's disease } \\
\text { Ulcer due to }\end{array}$ & 17 & 11 & $64 \cdot 7$ & 1 & 5.9 \\
\hline invagination & 2 & 1 & $50 \cdot 0$ & 0 & 0 \\
\hline \multicolumn{6}{|l|}{ Large intestine } \\
\hline Ulcerative colitis & 8 & 1 & $12 \cdot 5$ & 0 & 0 \\
\hline Tuberculosis & 7 & 0 & 0 & 0 & 0 \\
\hline $\begin{array}{l}\text { Crohn's disease } \\
\text { Ulcer due to }\end{array}$ & 3 & 2 & $66 \cdot 7$ & 1 & $33 \cdot 3$ \\
\hline $\begin{array}{l}\text { volvulus of sigmoid } \\
\text { colon }\end{array}$ & $d_{1}$ & 1 & 100 & 0 & 0 \\
\hline Total & 56 & 31 & 55.4 & 5 & 8.9 \\
\hline
\end{tabular}

large intestine showed pyloric gland metaplasia, two of three specimens with Crohn's disease in the large intestine revealed this condition. Pyloric gland metaplasia was also observed in each specimen of invagination of the small intestine and volvulus of the sigmoid colon.

True gastric metaplasia was recognised only in three specimens with tuberculosis $(16.7 \%)$ and two specimens with Crohn's disease $(5.9 \%)$. It was obvious, however, that the frequency of true gastric metaplasia was proportional to that of pyloric gland metaplasia in each disease category.

Clinical findings showed that in these five patients with true gastric metaplasia the duration of the disease varied from seven months to 20 years, although it was equivocal as some of the clinical data were not available. It was also recognised that two patients had intestinal strictures and corresponding proximal dilatation of the intestine. One of the two had undergone a side-to-side ileostomy to establish an ileal blind loop without removing the intestinal lesions.

\section{MICROSCOPIC FINDINGS}

Twenty-nine out of 31 specimens showing pyloric gland metaplasia had active ulcers of various stages, from freshly formed ulcer to the healed one remaining scar (Fig. 1). Although two specimens had no ulcers, they showed moderate degrees of submucosal fibrosis which were strongly suggestive of regenerated mucosal surface and the previous existence of active ulcers.

The extension of pyloric gland metaplasia and the severity of submucosal fibrosis varied from none to severe. It was evident that the degree of submucosal

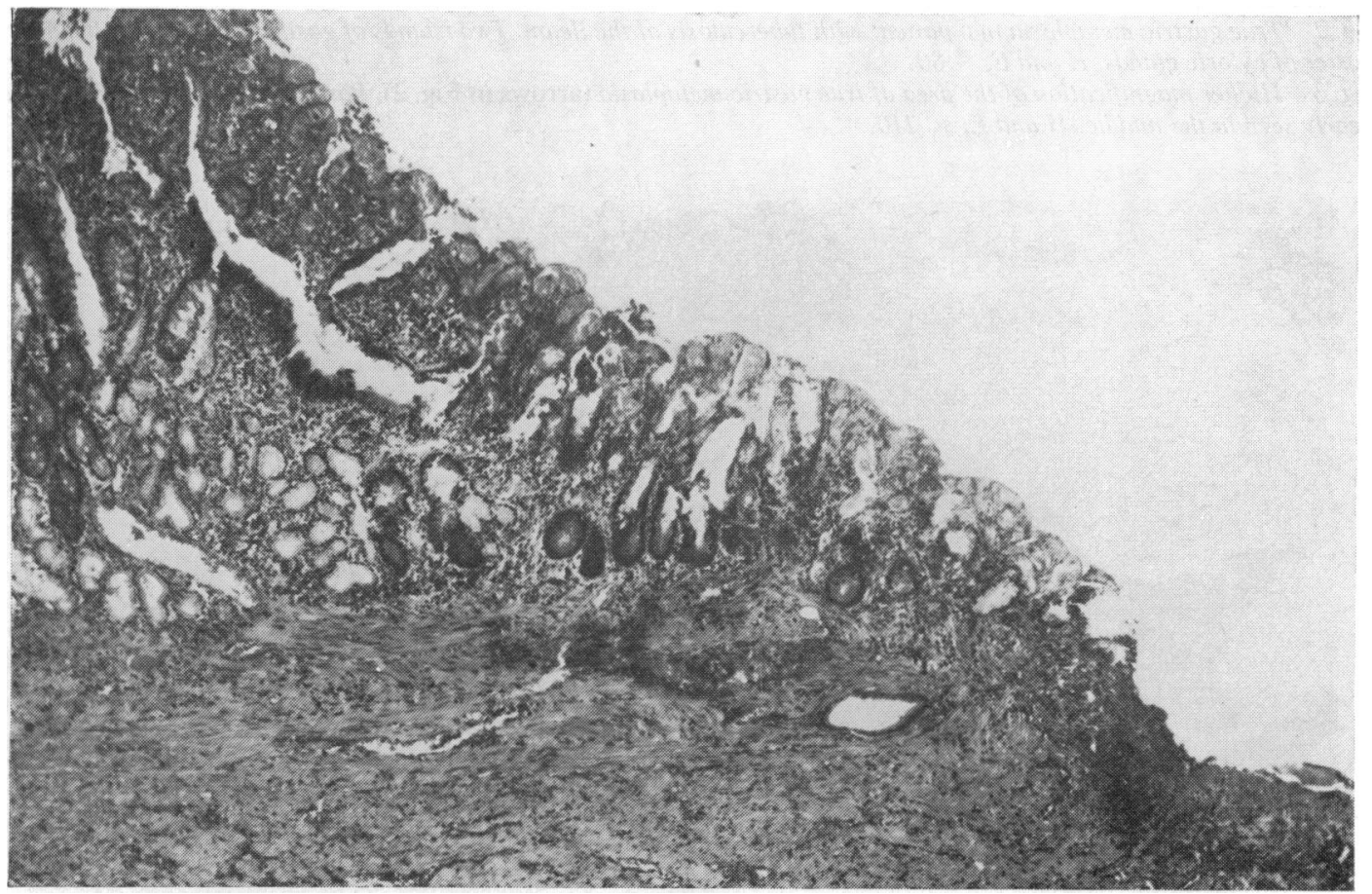

Fig. 1 Ulcer (right) and pyloric gland metaplasia in a patient with Crohn's disease of the ileum. In the base of the mucosa propria, islands of pyloric glands with brighter epithelium are seen on the left; crypts of Lieberkühn appear much darker. $H$ and $E, \times 60$. 


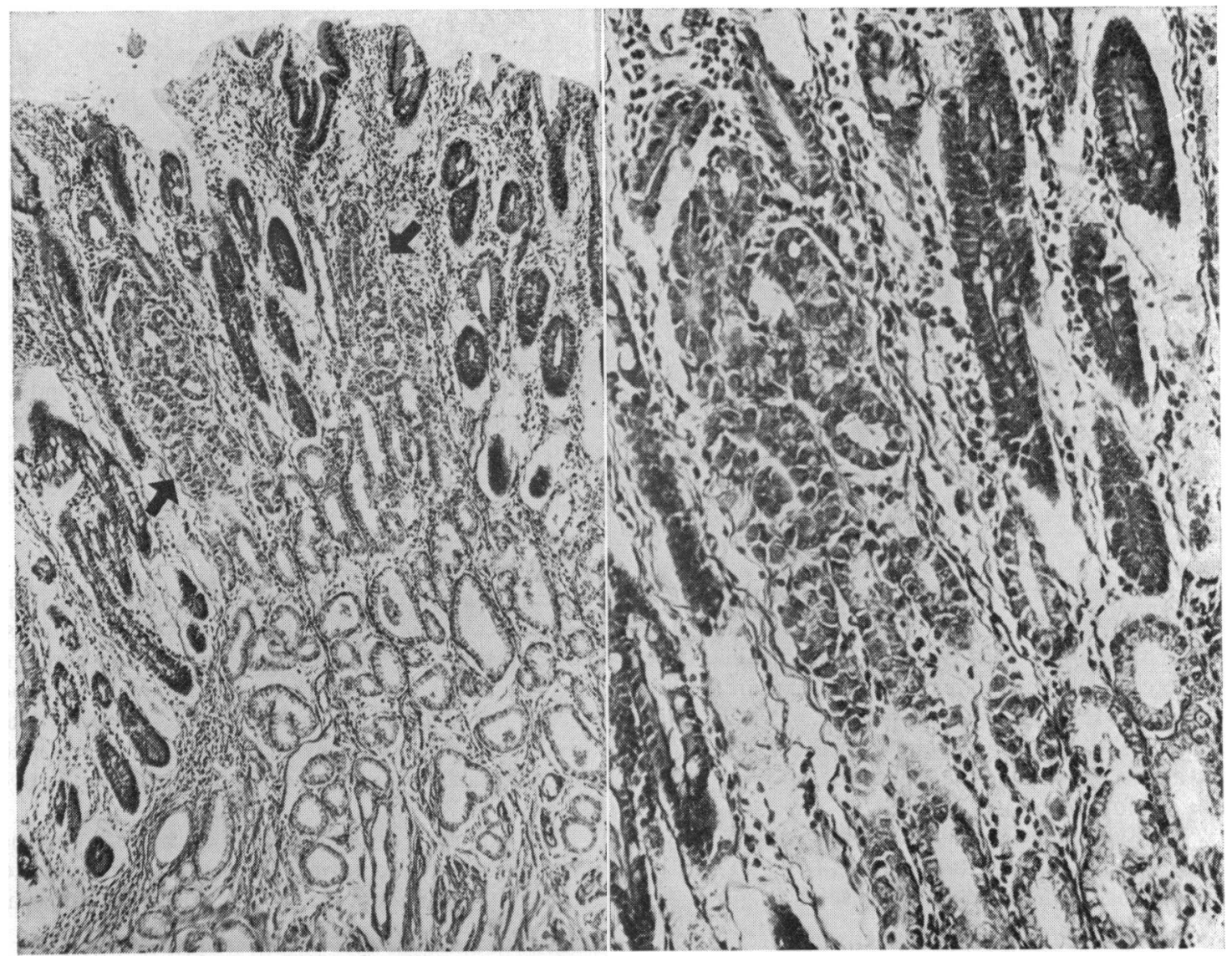

Fig. 2 True gastric metaplasia in a patient with tuberculosis of the ileum. Two islands of gastric glands are lying over a cluster of pyloric glands. $H$ and $E, \times \delta 0$.

Fig. 3 Higher magnification of the area of true gastric metaplasia (arrows in Fig. 2). Parietal and chief gastric cells are clearly seen in the middle. $H$ and $E, \times 210$.

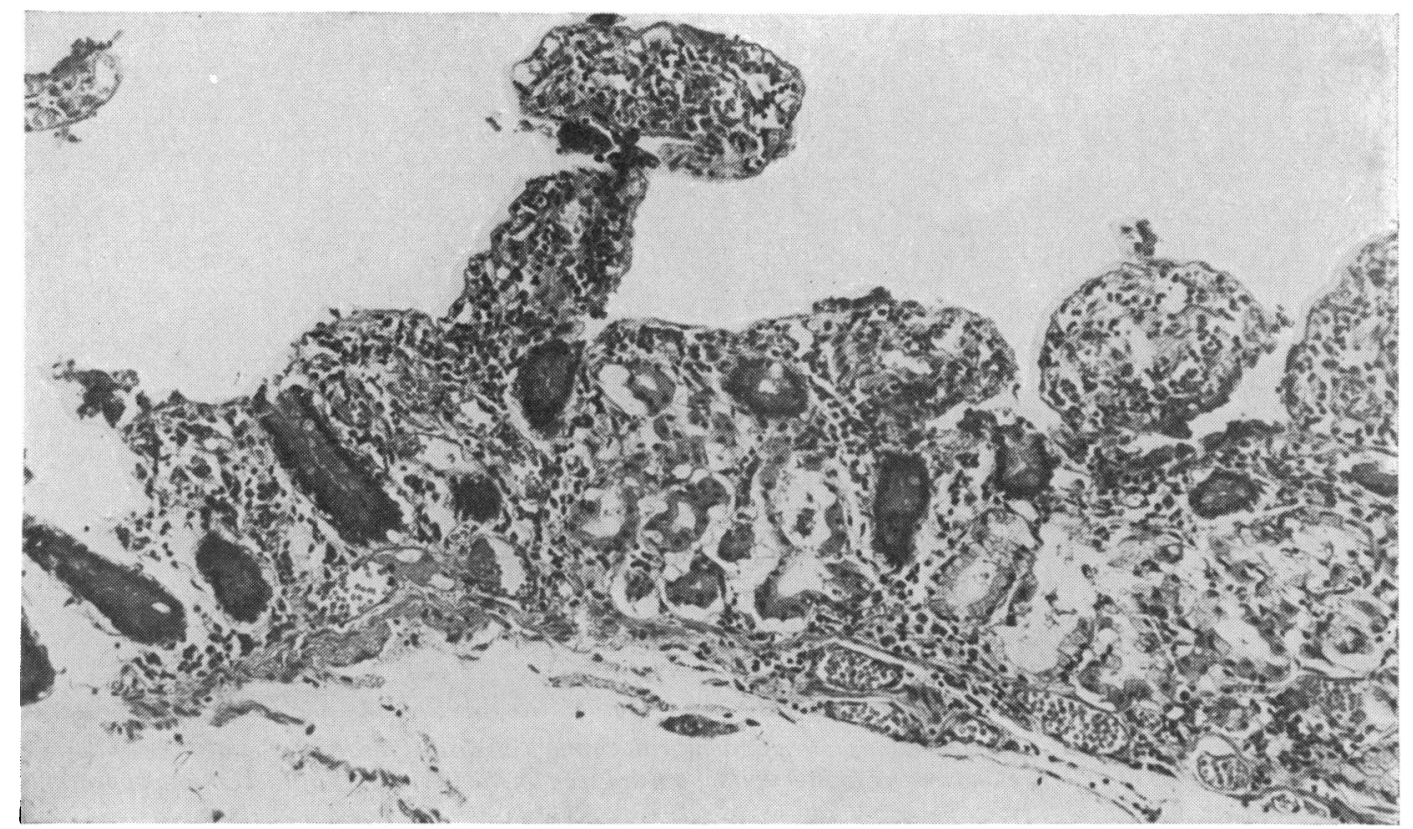

Fig. 4 True gastric metaplasia in a patient with Crohn's disease of the ileum. Islands of mature gastric glands consisting of parietal cells, chief cells, and mucous neck cells are clearly seen. $H$ and $E, \times 90$. 


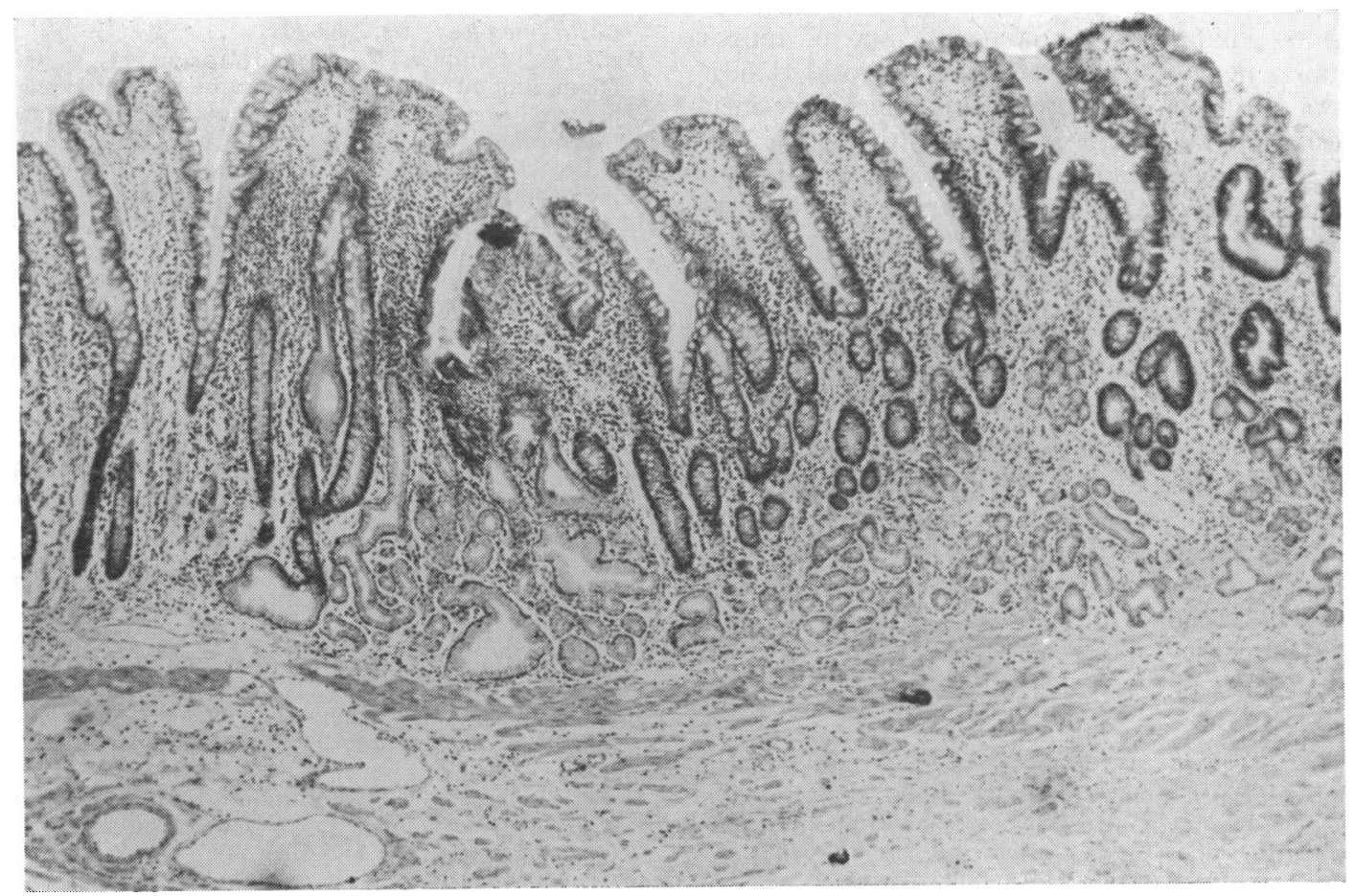

Fig. 5 Pyloric gland metaplasia in another patient with Crohn's disease of the ileum. Numerous pyloric glands and several dilated glands with lightly stained epithelium are seen in the deeper layer. Transition of dilated glands into pyloric glands is visible. $H$ and $E, \times 90$.

fibrosis correlated well with the severity of pyloric gland metaplasia.

True gastric metaplasia was recognised in five out of 31 specimens with pyloric gland metaplasia. Three of these five specimens with true gastric metaplasia showed moderate degrees of submucosal fibrosis and two showed severe submucosal fibrosis. As four of the five patients with true gastric metaplasia showed moderate degrees of pyloric gland metaplasia and one of them showed severe pyloric gland metaplasia, it was assumed that true gastric metaplasia seemed to appear more frequently in the area where pyloric gland metaplasia was extensive (Figs. 2, 3, and 4).

A noticeable feature was seen in most of the specimens: there were scattered dilated glands with lightly stained epithelium in the deep zone of the mucosa propria, particularly above the area where the muscularis mucosa adhered to the muscular layer, and they frequently exhibited transition into pyloric glands (Fig. 5).

\section{Discussion}

Aberrant gastric gland is the term that is used when gastric glands are found in an organ other than the stomach. This rare condition has been classified into two categories: gastric heterotopia and gastric metaplasia. The former is a congenital type of this entity, while the latter is an acquired condition. It is well known that gastric glands found in Meckel's diverticulum indicate heterotopia. Though found much less frequently, intestinal duplication is another instance of gastric heterotopia.

As mentioned in the introductory section of this paper several authors have reported on pyloric gland metaplasia in the intestine and Lee (1964) concluded that pyloric type glands were frequently found in various intestinal disorders while true gastric metaplasia in the intestine is of rare occurrence.

In the present study, as shown in the Table, the frequency of pyloric gland metaplasia in the intestine was as high as $55.4 \%$ in various ulcerative disorders and true gastric metaplasia developed in about $16 \%$ of patients with pyloric gland metaplasia.

As has already been pointed out by others (Ming et al. 1963), the destruction of the intestinal mucosa and its regeneration - that is, the response of the submucosal tissue to ulcer healing - was assumed to play an important part in the genesis of pyloric gland metaplasia. It seems that dilated glands with lightly 
stained epithelium in the deep zone of mucosa propria may be transformed into pyloric glands.

As, in most of the cases with true gastric metaplasia, islands of metaplastic gastric glands were never found in the area where there was no pyloric gland metaplasia, true gastric metaplasia was considered to be derived from metaplastic pyloric glands. In other words, metaplastic pyloric glands may well be described as 'immature glands' which have the potentiality of developing into either mature intestinal glands or parietal and chief gastric cells.

We therefore concluded that both pyloric gland metaplasia and true gastric metaplasia were nonspecific phenomena that were more frequently met with than had hitherto been thought, and this was particularly true where ulcerative intestinal disorders were concerned.

\section{References}

Antonius, J. I., Gump, F. E., Lattes, R., and Lepore, M. (1960). A study of certain microscopic features in regional enteritis, and their possible prognostic significance.
Gastroenterology, 38, 889-905.

Duffy, G., Enriquez, A. A., and Watson, W. C. (1974). Duplication of the ileum with heterotopic gastric mucosa, pseudomyxoma peritonei and nonrotation of the midgut. Gastroenterology, 67, 341-346.

Hoedemaeker, P. J. (1970). Heterotopic gastric mucosa in the duodenum. Digestion, 3, 165-173.

James, A. H. (1964). Gastric epithelium in the duodenum. Gut, 5, 285-294.

Lee, F. D. (1964). Pyloric metaplasia in the small intestine. Journal of Pathology and Bacteriorology, 87, 267-277.

Lee, S. M., Mosenthal, W. T., and Weismann, R. E. (1970). Tumorous heterotopic gastric mucosa in the small intestine. Archives of Surgery, 100, 619-622.

Liber, A. F. (1951). Aberrant pyloric glands in regional ileitis. Archives of Pathology, 51, 205-212.

Ming, S. C., Simon, M., and Tandon, B. N. (1963). Gross gastric metaplasia of ileum after regional enteritis. Gastroenterology, 44, 63-68.

Nawaz, K., Graham, D. Y., Fechner, R. E., Eiband, J. M. (1974). Gastric heterotopia in the ileum with ulceration and chronic bleeding. Gastroenterology, 66, 113-117.

Ripstein, C. B. (1949). Duplication of the small intestine. American Journal of Surgery, 78, 847-852.

Stockman, J. M., Young, V. T., and Jenkins, A. L. (1960). Duplication of the rectum containing gastric mucosa. Journal of the American Medical Association, 173, 12231225.

Trier, J. S., Moxey, P. C., Fordtran, J. S., and MacDermott, R. P. (1973). Ectopic gastric mucosa in celiac sprue. Gastroenterology, 65, 712-727. 